\title{
МЕТОД РОЗРАХУНКУ ДИФЕРЕНЦЙНОЇ ЩІЛЬНОСТІ ІМОВІРНІСНОГО ТРИПАРАМЕТРИЧНОГО ГАММА-РОЗПОДІЛУ ВИТРАТ СТОКУ РІЧКИ В ЗАДАЧАХ ГІДРОЕНЕРГЕТИКИ
}

\begin{abstract}
М.P. Ібрагімова
Інститут відновлюваної енергетики НАН України, 02094, м. Київ, вул. Гната Хоткевича, 20А

тел./факс +38-044-206-28-09, e-mail: hydro@ive.org.ua

Очікуваний у найближчому майбутньому дефіџит вуглеводнів, зростаючий тиск на екологію та ресурсозабезпечення існування людства - основні тригери трансформації енергетичної галузі відповідно до ухвалених на Саміті ООН Цілей сталого розвитку. Розвиток малої гідроенергетики також повинен відповідати раціональному використанню водного ресурсу, збереженню та можливому відновленню річкової системи, мінімізачії антропогенного впливу. Дана стаття спрямована на вирішення актуального питання створення малих гідроелектростанцій, технологічні режими роботи якої відповідають принципам рачіонального гідроенергетичного водокористування з врахуванням природоохоронних обмежень на використання води для виробнищтва електроенергії. Автором приведено переваги використання функції диференційної щільності імовірнісного розподілу витрат стоку річки над традиційно застосовуваною інтегральною функцією розподілу при аналізі гідроенергетичних показників експлуатації малих ГЕС. Проведений аналіз попередніх досліджень диференційної щільності засвідчив відсутність узагальнених результатів з визначення даної функиії у вигляді, необхідному для подальших практичних застосувань. Вперше розроблено прямий метод розрахунку функції диференційної щиільності імовірнісного трипараметричного гамма-розподілу витрат стоку річки за довільних значень коефіцієнтів варіації та асиметрії на основі застосування інтерполяції кубічними сплайнами в околі полюсів гамма-функції. Матеріали статті містять результати проведеного дослідження у вигляді таблиць значень функції диференційної щуільності імовірнісного гамма-розподілу витрат води. Зазначені таблиці рекомендуються до застосовування інженерними та проектними службами при виконанні гідрологічних та гідротехнічних розрахунків в задачах гідроенергетики. Бібл. 18, табл. 3, рис. 3.
\end{abstract}

Ключові слова: витрати води, імовірність, інтерполяція, диференційна щуільність, забезпеченість, розподіл.

\section{METHOD FOR THE CALCULATION OF PROBABILITY DENSITY FUNCTION OF THREE-PARAMETER GAMMA DISTRIBUTION OF RIVER FLOW DISCHARGE RELATED TO HYDROPOWER TASKS}

\author{
M. Ibragimova \\ Institute for Renewable Energy of NASU, \\ Kyiv, 20A, Hnata Khotkevycha Str., \\ Phone/fax: +38-044-206-28-09, e-mail: hydro@ive.org.ua
}

Hydrocarbon deficit, increasing pressure on the environment and problems of resource availability are the major triggers for the transformation of energy industry worldwide. The development of small hydropower also should conform to the principles of rational use of water resources, river conservation and restoration, reducing the human impact, etc. The article focuses on a pressing issue of construction of small hydroelectric power plant with operation modes that comply sustainable water use taking into account environmental constraints on the use of water for electricity generation. The author presents the advantages of density function of probability distribution of river flow discharge over its cumulative probability as a means of analyzing performance indicators of small hydroelectric power plants. The review of previous studies of probability density function showed the absence of summarized results required for further practical applications of this function. There have been developed, for the first time, a method for the calculation of the probability density function of three-parameter Gamma distribution of river flow discharge at random coefficients of variation and asymmetry by cubic spline interpolation in the vicinity of the poles of Gamma function. The article contains the results of a study of probability Gamma distribution of river flow discharge in tabular form of relevant density function values. These tables are recommended for hydropower engineering and design services when performing hydrological and hydrotechnical calculations. Ref. 18, tab. 3, fig. 3.

Keywords: flow discharge, probability, interpolation, probability density function, availability, distribution.

(C) М.Р. Ібрагімова, 2019

Відновлювана енергетика. 2019. № 3 


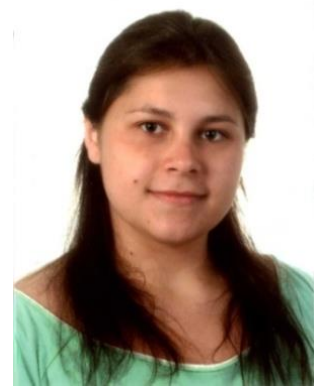

М.Р. Ібрагімова M. Ibragimova
Відомості про автора: науковий співробітник відділу гідроенергетики, Інститут відновлюваної енергетики Національної академії наук України. Освіта: НТУУ «Київський політехнічний інститут».

Спеціальність «Нетрадиційні і відновлювані джерела енергії».

Наукова сфера: альтернативна енергетика, перетво- Research area: alternative energy, conversion of рення відновлюваних видів енергії, мала гідроенерге- renewable energy, small hydropower, energy conтика, енергозбереження та енергоефективність.

Публікації: 20.

ORCID: 0000-0003-1732-4477.

e-mail: mariaibragimovar@gmail.com
Author information: junior research fellow at $\mathrm{Hy}-$ dropower Department, Institute for Renewable Energy of National Academy of Sciences of Ukraine. Education: National Technical University of Ukraine «Kyiv Polytechnic Institute»;

Specialty «Non-traditional and renewable energy sources». servation and efficiency.

Publications: 20.

ORCID: 0000-0003-1732-4477.

e-mail: mariaibragimovar@gmail.com
Перелік використаних позначень та скорочень:

ГЕС - гідроелектростанція;

$P \quad$ - забезпеченість (імовірність перевищення) заданої величини;

$p$ - диференційна щільність імовірнісного розподілу;

$\gamma, b$ - параметри ймовірнісного розподілу;

$Q \quad$ - витрата води;

Вступ. У довгостроковій перспективі розвитку енергетичної галузі відзначено необхідність скорочення частки викопного та ядерного палива і відповідно їх заміщення відновлюваними та альтернативними джерелами енергії. 3 одного боку, вже сьогодні створені певні механізми стимулювання державою виробництва електроенергії об'єктами відновлюваної енергетики: «зелений» тариф і надбавки за використання обладнання українського виробництва, пільги в оподаткуванні, пільговий режим приєднання до електричної мережі тощо. Перед малою гідроенергетикою постає завдання створення малих гідроелектростанцій (ГЕС) із врахуванням природоохоронних вимог, що спрямовані на максимально можливе збереження природного середовища річки. У подальшому викладенні малу ГЕС, технологічні режими роботи якої відповідають принципам раціонального гідроенергетичного водокористування 3 врахуванням природоохоронних обмежень на використання води для виробництва електроенергії, будемо називати «зеленою» малою ГЕС. Створенню такої станції повинен передувати багатостадійний процес проектування 3 теоретичним обгрунтування технічних параметрів і експлуатаційних режимів функціонування на основі застосування імовірнісних
$Q_{c p}-$ середня багаторічна витрата води;

$K_{P}$ - модульний коефіцієнт витрат води стоку річки;

$C_{V}-$ коефіцієнт варіації витрат води;

$C_{S}$ - коефіцієнт асиметрії витрат води;

$\Gamma$ - гамма-функція.

розподілів витрат води стоку річки [1-6].

Постановка завдання. В задачах гідроенергетики найбільшого поширення набув імовірнісний трипараметричний розподіл витрат води стоку річки [5-9]. Відомо, що вичерпною оцінкою випадкової величини $є$ іiі інтегральна або диференційна функції розподілу. Проте традиційно в гідроенергетичних розрахунках застосовується виключно інтегральна функція розподілу, яка надає можливості для визначення параметрів гідрологічного режиму через оцінку імовірності за рівнем забезпеченості витрат води стоку з метою наступного обгрунтування проектних рішень. Зокрема, гідротехнічні споруди 3 регулювання стоку річки розраховуються саме по водності року певної заданої забезпеченості (див. Таблицю 1), що гарантує надійність та очікувану безвідмовність роботи споруд. Для визначення гарантованої та встановленої потужностей ГЕС традиційної реалізації з акумулюванням водотоку у водосховищі також достатньо використання інтегральної характеристики функції розподілу, або забезпеченості, як основи гідроенергетичних розрахунків. Тому в спеціалізованих виданнях [9-11] наведені табульовані значення ординат кривих забезпеченостей відповідних розподілів за фіксованих значень коефіцієнтів варіації та асиметрії.

Таблиця 1. Повторюваність і забезпеченість витрати води стоку річки характерних років [12].

Table 1. Frequency and availability of river flow discharge of of indicative years [12].

\begin{tabular}{|l|l|l|}
\hline \multicolumn{1}{|c|}{ Характеристика водності року } & \multicolumn{1}{|c|}{ Повторюваність, 1 раз в $n$ років $n$, років } & Забезпеченість, $P, \%$ \\
\hline Дуже багатоводний & 100 & 1 \\
\hline Середній багатоводний & 10 & 10 \\
\hline Помірно багатоводний & 4 & 25 \\
\hline Середньої водності & 2 & 50 \\
\hline Помірно маловодний & 4 & 75 \\
\hline Середній маловодний & 10 & 90 \\
\hline Дуже маловодний & 33 & 97 \\
\hline Катастрофічно маловодний & 100 & 100 \\
\hline
\end{tabular}


Проте сучасні положення щодо будівництва та наступної експлуатації малих ГЕС із дотриманням природоохоронних критеріїв функціонування диктують потребу встановлення нових підходів у проведенні гідроенергетичних розрахунків, що враховуватимуть обмеження на використання води для виробництва електроенергії: обмеження на використання води у межень, повені та паводки; санітарний попуск; оперативні заходи з регулювання водного потоку через гідроспоруди; безперервне функціонування рибоходів; регулювання потужності по водотоку [13]. За даних умов, спрямованих на збереження первісного стану русла водотоку, визначальним фактором оцінки проектних параметрів малої ГЕС $є$ значення витрат води стоку, або, іншими словами, надходження води до створу станції. Тому адекватна методика аналізу гідроенергетичних показників експлуатації «зелених» малих ГЕС повинна грунтуватись на застосуванні функції диференційної щільності імовірнісного розподілу витрат стоку річки.

В загальному випадку, функція диференційної щільності імовірнісного розподілу дає змогу визначити імовірність $F$ попадання випадкової величини $X$ у будь-яку задану область [10], наприклад обмежену інтервалом $\left[a_{1}, a_{2}\right]$ :

$$
\begin{gathered}
p\left\{Q ; Q_{c p} ; \gamma, b\right\}=\left[\frac{\Gamma(\gamma+b)}{\Gamma(\gamma)}\right]^{\gamma / b} \frac{1}{\Gamma(\gamma)|b| Q_{c p}}\left(\frac{Q}{Q_{c p}}\right)^{\gamma / b-1} \times \\
\times \exp \left\{-\left[\frac{Q}{Q_{c p}} \cdot \frac{\Gamma(\gamma+b)}{\Gamma(\gamma)}\right]^{1 / b}\right\}, Q>0,
\end{gathered}
$$

де $Q$ - випадкова величина витрат води, м³/с; $Q_{c p}$ - середня багаторічна витрата води, $\mathrm{m}^{3} / \mathrm{c}$;

$Q / Q_{c p}=K_{P}-$ модульний коефіцієнт витрат води;

$\gamma, b$ - параметри, яким відповідають певні значення коефіцієнта варіації $C_{V}$ та асиметрії $C_{S}$ витрат води стоку річки.

Параметри розподілу $\gamma$ і $b$ можуть бути визначені з системи рівнянь, що встановлює зв'язок між параметрами $\gamma$ i $b$ та стандартними гідрологічними параметрами стоку витрат води $C_{V}$ i $C_{S}$ :

$$
\left\{\begin{array}{l}
C_{V}=\left[\frac{\Gamma(\gamma) \Gamma(\gamma+2 b)}{\Gamma^{2}(\gamma+b)}-1\right]^{1 / 2}, \\
C_{S}=\frac{\frac{\Gamma^{2}(\gamma) \Gamma(\gamma+3 b)}{\Gamma^{3}(\gamma+b)}-\frac{3 \Gamma(\gamma) \Gamma(\gamma+2 b)}{\Gamma^{2}(\gamma+b)}+2}{\left[\frac{\Gamma(\gamma) \Gamma(\gamma+2 b)}{\Gamma^{2}(\gamma+b)}-1\right]^{3 / 2}},
\end{array}\right.
$$

де $\Gamma(\gamma), \Gamma(\gamma+2 b)$ та ін. - гамма-функції відповідних аргументів.

$$
F\left\{a_{1}<X \leq a_{2}\right\}=\int_{a_{1}}^{a_{2}} p(x) d x,
$$

де $p(x)$ - функція диференційної щільності імовірнісного розподілу.

При цьому обчислення ординат кривих забезпеченості розподілу виконується шляхом визначення інтеграла від функції диференційної щільності

$$
P\left\{x>x_{P}\right\}=1-\int_{0}^{x_{P}} p(x ; \gamma, b) d x,
$$

де $P$-ймовірність перевищення (забезпеченість) значення шуканої ординати $x_{P} ; p(x ; \gamma, b)$-диференційна щільність ймовірностей за параметрів розподілу $x, \gamma, b$.

Проте варто зазначити, що в попередніх дослідженнях відсутні узагальнені результати 3 визначення функції диференційної щільності у вигляді, необхідному для подальших практичних застосувань, аналогічно інтегральним показникам розподілу.

Рівняння диференційної щільності трипараметричного гамма-розподілу у функції витрат води, рекомендованого нормативним документом [11], має наступний вид:

Після перетворень система (4) представляється у вигляді:

$$
\left\{\begin{array}{l}
\frac{\Gamma(\gamma) \Gamma(\gamma+2 b)}{\Gamma^{2}(\gamma+b)}=K_{1}, \\
\frac{\Gamma(\gamma+b) \Gamma(\gamma+3 b)}{\Gamma^{2}(\gamma+2 b)}=K_{2},
\end{array}\right.
$$

де $K_{1}=1+C_{V}^{2}, K_{2}=\left[C_{S} C_{V}^{3}+3\left(1+C_{V}^{2}\right)-2\right] /\left(1+C_{V}^{2}\right)^{2}-$ відомі для заданих значень $C_{V}$ i $C_{S}$.

В логарифмічній формі рівняння набувають остаточного виду, прийнятного для виконання практичних розрахунків:

$$
\left\{\begin{array}{l}
f_{1}=\ln \Gamma(\gamma)+\ln \Gamma(\gamma+2 b)-2 \ln \Gamma(\gamma+b)-\ln K_{1}=0, \\
f_{2}=\ln \Gamma(\gamma+b)+\ln \Gamma(\gamma+3 b)-2 \ln \Gamma(\gamma+2 b)-\ln K_{2}=0 .
\end{array}\right.
$$

Результати. Сучасні програмні продукти дають можливість виконувати складні та об'ємні розрахунки аналізу і обробки даних. Числове вирішення системи трансцендентних рівнянь (6) було реалізовано за допомогою нелінійної оптимізації методом довірчих областей у програмному пакеті MATLAB. Задача даного розрахунку зводиться до ітераційного пошуку параметрів $\gamma$ i $b$, кожній комбінації яких відповідають задані значення коефіцієнта варіації $C_{V}$ та асиметрії $C_{S}$. В якості першого наближення шуканих парамет- 
рів були прийняті округлені до десятих значення величин $\gamma$ i $b$, наведених у [9].

Результати отримано для діапазону зміни коефіцієнта $C_{V}$ від 0,1 до 2 включно, 3 кроком 0,1; а коефіцієнт $C_{S}$ задано як відношення $C_{V} / C_{S}$, значення якого відповідає діапазону від 1 до 4, 3 кроком 0,5. Відомо, що в околі полюсів гамма-функції
$\left(C_{v}=0,30 ; C_{s}=3 \cdot C_{v}\right),\left(C_{v}=0,70 ; C_{s}=3,5 \cdot C_{v}\right)$ i $\left(C_{v}=1,00 ;\right.$ $\left.C_{s}=4 \cdot C_{v}\right)$ параметр $\gamma$ необмежено зростає, що зумовлює значне зниження точності обчислень і тим самим унеможливлює отримання достовірних результатів у цих областях. На рис.1 графічно зображено результат визначення параметра $\gamma$ за довільних значень коефіцієнтів варіації та асиметрії.

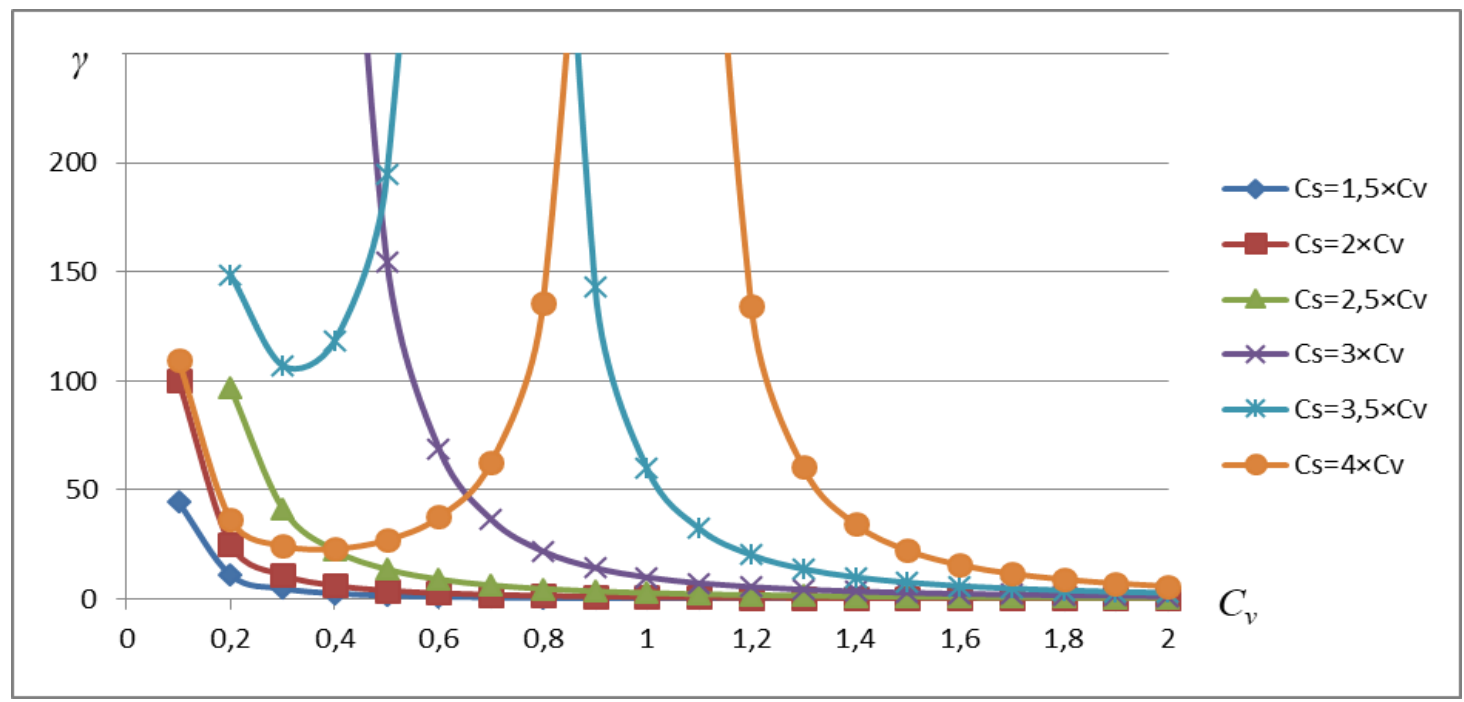

Рис. 1. Залежність параметра $\gamma$ від $C_{V}$ та $C_{V} / C_{S}$.

Fig. 1. Dependence of $\gamma$ parameter on $C_{V}$ and $C_{V} / C_{S}$.

3 метою дослідження впливу зазначеної осо- лено одержаний результат, а саме, множину знабливості гамма-функції на результат визначення чень функції диференційної щільності при функції диференційної щільності виконано відповідний розрахунок для одного з характерних випадків $C_{S} / C_{V}=4$. На рис.2 графічно представ-

$C_{S} / C_{V}=4$. Встановлено, що за параметрів $C_{V}=0,9 \div 1,1$ функція $p(x)$ невизначена.

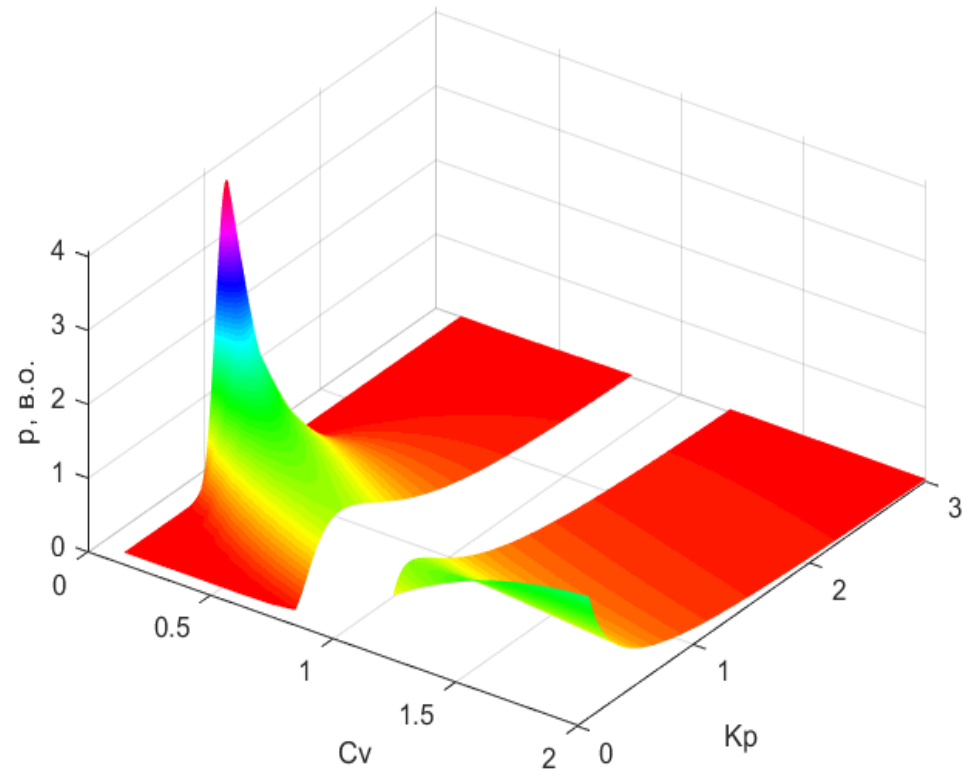

Рис. 2. Множина значень диференційної функції трипараметричного гамма-розподілу витрат води у модульних коефіціснтах $K_{P}$ при $C_{S} / C_{V}=4$.

Fig. 2. Values of probability density function of three-parameter Gamma distribution of river flow discharge in coefficients $K_{P}$ at $C_{S} / C_{V}=4$. 
Для розв'язання задачі визначення функції диференційної щільності у всьому діапазоні довільних значень їі аргументів, у тому числі в околі полюсів гамма-функції, була застосована інтерполяційна процедура 3 використанням кубічних сплайн-функцій двох змінних 3 неперервними похідними до другого порядку включно в точках інтерполяції. Наведемо найпростіший випадок визначення простору сплайнів.

$$
\begin{aligned}
& \text { Нехай в прямокутній області } \\
& \Omega=[c, d] \times[g, h] \quad \text { задана сітка ліній } \\
& \Delta=\Delta_{C_{V}} \times \Delta_{K_{P}} \text {, де } \\
& \Delta_{C_{V}}: c=C_{V_{0}}<C_{V_{1}}<\ldots<C_{V_{m}}=d, \\
& \Delta_{K_{P}}: g=K_{P_{0}}<K_{P_{1}}<\ldots<K_{P_{n}}=h,
\end{aligned}
$$

що ділить область $\Omega$ на прямокутні комірки

$$
\begin{aligned}
\Omega_{i j} & =\left\{\left(C_{V}, K_{P}\right) \mid C_{V} \in\left[C_{V_{i}}, C_{V_{i+1}}\right], K_{P} \in\left[K_{P_{j}}, K_{P_{j+1}}\right]\right\}, \\
i & =0,1, \ldots, m ; j=0,1, \ldots, n .
\end{aligned}
$$

В такому випадку шукана поверхня значень функції диференційної щільності $p\left(C_{V_{i}}, K_{P_{j}}\right)$ формується кубічним інтерполяційним сплайном двох змінних [14-16]:

$$
S\left(C_{V}, K_{P}\right)=\sum_{\alpha=0}^{3} \sum_{\beta=0}^{3} a_{\alpha \beta}^{i j}\left(C_{V}-C_{V_{i}}\right)^{\alpha}\left(K_{P}-K_{P_{j}}\right)^{\beta},
$$

де $a_{\alpha \beta}^{i j}-$ коефіцієнти сплайна.

При цьому існування сплайна вимагає виконання наступної умови:

$$
S\left(C_{V_{i}}, K_{P_{j}}\right)=p_{i j} i=0,1, \ldots, m ; j=0,1, \ldots, n .
$$

а також граничних умов одного із чотирьох ти- пів, наприклад умов I-го типу:

$$
\begin{aligned}
& \frac{\partial S}{\partial C_{V}}\left(C_{V_{i}}, K_{P_{j}}\right)=p_{i j}^{\left(C_{V}\right)}, \quad i=0, m, j=0,1, \ldots, n, \\
& \frac{\partial S}{\partial K_{P}}\left(C_{V_{i}}, K_{P_{j}}\right)=p_{i j}^{\left(K_{P}\right)}, \quad i=0,1, \ldots, m, j=0, n, \\
& \frac{\partial^{2} S}{\partial C_{V}}\left(C_{V_{i}}, K_{P_{j}}\right)=p_{i j}^{\left(C_{V}, K_{P}\right)}, i=0, m, j=0, n,
\end{aligned}
$$

тобто в граничних вузлах сітки $\Delta$ задаються значення перших часткових похідних по $C_{V}$ i по $K_{P}$ шуканої функції, а в кутових вузлах - значення 2-ої змішаної похідної [15].

3 метою уникнення можливих спотворень в областях максимума, де I-ша похідна досліджуваної функції змінює свій знак, апроксимація областей виконувалась сплайном 1-го ступеня або лінійною інтерполяцією. Для апроксимації решти областей застосовано інтерполяцію кубічними сплайнами.

За результатом програмної реалізації процесу інтерполяції одержано множину значень диференційної функції імовірнісного розподілу витрат води, заданих у модульних коефіцієнтах $K_{P}$, відносно зміни коефіцієнта варіації $C_{V}$ та заданого значення $C_{S} / C_{V}=4$. Дана множина значень досліджуваної функції візуалізована неперервною поверхнею на рис.3 як результат доповнюючих одне одну лінійної на сплайнової інтерполяції. В таблиці 2 окремо представленні числові значення функції диференційної щільності в області іiї невизначеності, одержані завдяки застосуванню інтерполяції кубічними сплайнами в околі полюсів гамма-функції.

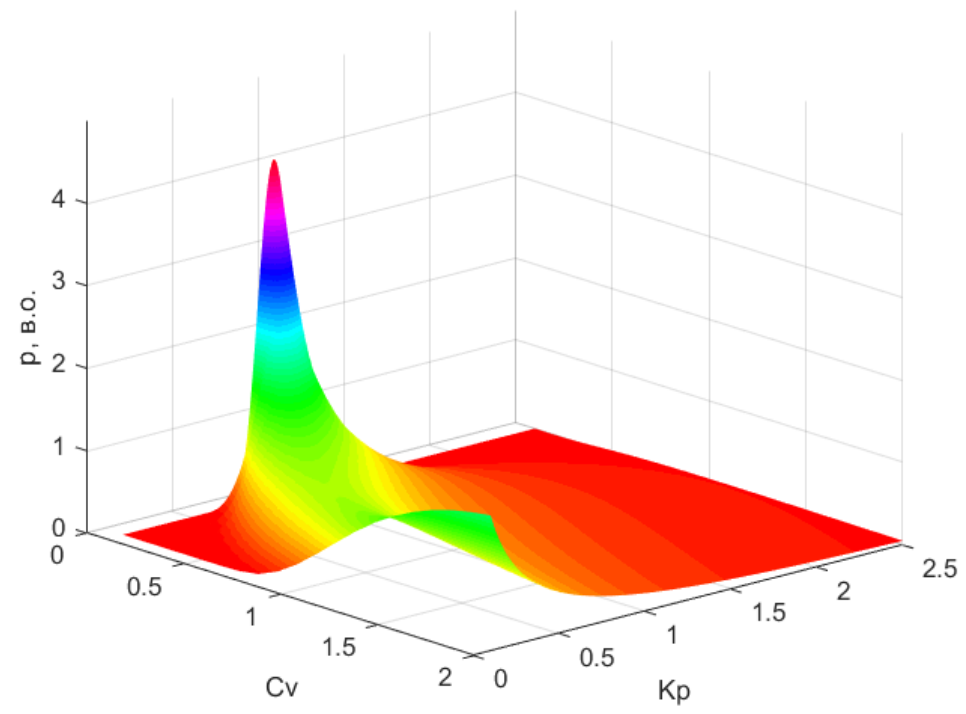

Рис. 3. Ординати диференційної функції імовірнісного розподілу витрат води у модульних коефіціснтах $K_{P}$ при $C_{S} / C_{V}=4$.

Fig. 3. Ordinates of probability density function of river flow discharge in coefficients $K_{P}$ at $C_{S} / C_{V}=4$. 
Таблиця 2. Числовий результат сплайнової інтерполяції функції диференційної щільності імовірнісного трипараметричного гамма-розподілу при $C s / C v=4$.

Table 2. Numerical result of spline interpolation of probability density function for three-parameter Gamma distribution at $C s / C v=4$.

\begin{tabular}{|l|c|c|c|c|c|}
\hline \multirow{2}{*}{$\boldsymbol{K} \boldsymbol{P}, \mathbf{B . 0 .}$} & \multicolumn{5}{|c|}{ Kоефіціснт варіації, $\boldsymbol{C}_{\boldsymbol{V}}$} \\
\cline { 2 - 6 } & $\mathbf{0 , 8}$ & $\mathbf{0 , 9}$ & $\mathbf{1 , 0}$ & $\mathbf{1 , 1}$ & $\mathbf{1 , 2}$ \\
\hline $\mathbf{0 , 1}$ & 0,0446 & 0,1489 & 0,3108 & 0,5088 & 0,7215 \\
\hline $\mathbf{0 , 2}$ & 0,3736 & 0,5680 & 0,7450 & 0,8951 & 1,0084 \\
\hline $\mathbf{0 , 3}$ & 0,7282 & 0,8590 & 0,9402 & 0,9827 & 0,9975 \\
\hline $\mathbf{0 , 4}$ & 0,9169 & 0,9519 & 0,9530 & 0,9314 & 0,8989 \\
\hline $\mathbf{0 , 5}$ & 0,9590 & 0,9265 & 0,8826 & 0,8330 & 0,7836 \\
\hline $\mathbf{0 , 6}$ & 0,9144 & 0,8476 & 0,7847 & 0,7267 & 0,6747 \\
\hline $\mathbf{0 , 7}$ & 0,8291 & 0,7508 & 0,6842 & 0,6275 & 0,5788 \\
\hline $\mathbf{0 , 7 5}$ & 0,7803 & 0,7018 & 0,6366 & 0,5823 & 0,5361 \\
\hline $\mathbf{0 , 8}$ & 0,7304 & 0,6540 & 0,5915 & 0,5401 & 0,4968 \\
\hline $\mathbf{0 , 8 5}$ & 0,6809 & 0,6081 & 0,5491 & 0,5010 & 0,4606 \\
\hline $\mathbf{0 , 9}$ & 0,6327 & 0,5644 & 0,5095 & 0,4648 & 0,4274 \\
\hline $\mathbf{0 , 9 5}$ & 0,5865 & 0,5233 & 0,4726 & 0,4314 & 0,3970 \\
\hline $\mathbf{1}$ & 0,5428 & 0,4849 & 0,4384 & 0,4006 & 0,3690 \\
\hline $\mathbf{1 , 0 5}$ & 0,5016 & 0,4492 & 0,4068 & 0,3723 & 0,3433 \\
\hline $\mathbf{1 , 1}$ & 0,4631 & 0,4160 & 0,3777 & 0,3462 & 0,3197 \\
\hline $\mathbf{1 , 1 5}$ & 0,4274 & 0,3853 & 0,3508 & 0,3222 & 0,2980 \\
\hline $\mathbf{1 , 2}$ & 0,3942 & 0,3569 & 0,3259 & 0,3001 & 0,2781 \\
\hline $\mathbf{1 , 3}$ & 0,3353 & 0,3064 & 0,2819 & 0,2609 & 0,2428 \\
\hline $\mathbf{1 , 4}$ & 0,2853 & 0,2635 & 0,2444 & 0,2276 & 0,2128 \\
\hline $\mathbf{1 , 5}$ & 0,2431 & 0,2271 & 0,2125 & 0,1992 & 0,1872 \\
\hline $\mathbf{1 , 6}$ & 0,2075 & 0,1962 & 0,1853 & 0,1749 & 0,1652 \\
\hline $\mathbf{1 , 7}$ & 0,1775 & 0,1700 & 0,1620 & 0,1540 & 0,1463 \\
\hline $\mathbf{1 , 8}$ & 0,1522 & 0,1476 & 0,1421 & 0,1360 & 0,1300 \\
\hline $\mathbf{1 , 9}$ & 0,1308 & 0,1285 & 0,1249 & 0,1205 & 0,1158 \\
\hline $\mathbf{2}$ & 0,1127 & 0,1122 & 0,1101 & 0,1070 & 0,1035 \\
\hline $\mathbf{2 , 5}$ & 0,0557 & 0,0590 & 0,0608 & 0,0614 & 0,0612 \\
\hline $\mathbf{3}$ & 0,0292 & 0,0328 & 0,0354 & 0,0371 & 0,0382 \\
\hline
\end{tabular}

Вищевикладені результати відповідають дослідженню функції диференційної щільності імовірнісного трипараметричного гамма-розподілу витрат води у випадку необмеженого зростання параметра $\gamma$ в околі полюса гамма-функції при $C_{V}=1,0 ; C_{S}=4 \cdot C_{V}$. Аналогічно було досліджено диференційну щільність в передбачуваних областях невизначеності функції, а саме в околі полюсів гамма-функції за комбінацій: $\left(C_{V}=0,3 ; C_{S}=3 \cdot C_{V}\right),\left(C_{V}=0,7 ; C_{S}=3,5 \cdot C_{V}\right)$. $\mathrm{y}$ кінцевому результаті, з використанням засобів інженерної геометрії програмно реалізовано визначення функції диференційної щільності імовірнісного гамма-розподілу витрат води, заданих модульними коефіцієнтами $K_{P}$ у повному діапазоні зміни коефіцієнта варіації $C_{V}$ та співвідношення $C_{S} / C_{V}$. Для практичного використання отриманих результатів дослідження сформовано таблиці значень функції диференційної щільності імовірнісного гамма-розподілу витрат води, заданих модульними коефіцієнтами $K_{P}$, за зміни коефіцієнта варіації $C_{V}$ в діапазоні $0,1 \div 23$ кроком 0,1 та $C_{S} / C_{V}=1 ; 1,5 ; 2 ; 2,5 ; 3 ; 3,5 ; 4$. Ці таблиці можуть безпосередньо застосовуватись інженерними та проектними службами при виконанні гідрологічних та гідротехнічних розрахунків річок з будь-якими гідрологічними параметрами стоку. Необхідність отримання даних за гідрологічних параметрів стоку, що не представлені в таблицях, наприклад за $C_{V}=0,42$ i $C_{S} / C_{V}=1,95$ (відповідають параметрам р. Південний Буг) [17,18], передбачає виконання інтерполяції табличних значень. Нижче, як варіант, представлено таблицю 3 значень функції диференційної щільності імовірнісного гаммарозподілу витрат води у модульних коефіцієнтах $K_{P}$ за зміни коефіцієнта варіації $C_{V}$ в діапазоні $0,1 \div 2$ з кроком 0,1 при $C_{S} / C_{V}=2$ (значення, найбільш характерне для території України). 
Таблиця 3. Значення функції диференційної щільності імовірнісного трипараметричного гамма-розподілу $C s / C v=2$.

Table 3. Values of probability density function for three-parameter Gamma distribution at $C s / C v=2$.

\begin{tabular}{|c|c|c|c|c|c|c|c|c|c|c|}
\hline \multirow{2}{*}{$\kappa_{P}, \mathbf{\text { в.o. }}$} & \multicolumn{10}{|c|}{ Коефіцієнт варіації, $C_{V}$} \\
\hline & 0,1 & 0,2 & 0,3 & 0,4 & 0,5 & 0,6 & 0,7 & 0,8 & 0,9 & $\mathbf{1 , 0}$ \\
\hline 0,1 & 0,0000 & 0,0000 & 0,0000 & 0,0001 & 0,0063 & 0,0505 & 0,1682 & 0,3527 & 0,5674 & 0,7765 \\
\hline $\mathbf{0 , 2}$ & 0,0000 & 0,0000 & 0,0001 & 0,0117 & 0,0894 & 0,2521 & 0,4483 & 0,6268 & 0,7651 & 0,8603 \\
\hline $\mathbf{0 , 3}$ & 0,0000 & 0,0000 & 0,0070 & 0,0951 & 0,2905 & 0,4988 & 0,6584 & 0,7594 & 0,8127 & 0,8323 \\
\hline 0,4 & 0,0000 & 0,0008 & 0,0694 & 0,3013 & 0,5415 & 0,6977 & 0,7750 & 0,7996 & 0,7931 & 0,7695 \\
\hline 0,5 & 0,0000 & 0,0226 & 0,2776 & 0,5888 & 0,7599 & 0,8185 & 0,8164 & 0,7857 & 0,7433 & 0,6973 \\
\hline 0,6 & 0,0001 & 0,1870 & 0,6444 & 0,8636 & 0,9015 & 0,8657 & 0,8061 & 0,7422 & 0,6812 & 0,6255 \\
\hline 0,7 & 0,0197 & 0,6870 & 1,0493 & 1,0510 & 0,9593 & 0,8568 & 0,7639 & 0,6840 & 0,6160 & 0,5582 \\
\hline 0,75 & 0,1227 & 1,0530 & 1,2151 & 1,1019 & 0,9607 & 0,8372 & 0,7355 & 0,6524 & 0,5839 & 0,5267 \\
\hline 0,8 & 0,4924 & 1,4323 & 1,3364 & 1,1245 & 0,9473 & 0,8103 & 0,7042 & 0,6202 & 0,5525 & 0,4967 \\
\hline $\mathbf{0 , 8 5}$ & 1,3410 & 1,7581 & 1,4065 & 1,1214 & 0,9217 & 0,7781 & 0,6709 & 0,5880 & 0,5220 & 0,4683 \\
\hline 0,9 & 2,5912 & 1,9745 & 1,4250 & 1,0964 & 0,8866 & 0,7421 & 0,6366 & 0,5562 & 0,4928 & 0,4414 \\
\hline 0,95 & 3,6869 & 2,0522 & 1,3969 & 1,0537 & 0,8445 & 0,7035 & 0,6019 & 0,5251 & 0,4648 & 0,4161 \\
\hline 1 & 3,9861 & 1,9928 & 1,3304 & 0,9976 & 0,7975 & 0,6636 & 0,5675 & 0,4949 & 0,4380 & 0,3922 \\
\hline 1,05 & 3,3637 & 1,8224 & 1,2355 & 0,9322 & 0,7475 & 0,6232 & 0,5336 & 0,4658 & 0,4126 & 0,3697 \\
\hline 1,1 & 2,2671 & 1,5802 & 1,1219 & 0,8610 & 0,6961 & 0,5830 & 0,5006 & 0,4379 & 0,3885 & 0,3485 \\
\hline 1,15 & 1,2451 & 1,3067 & 0,9988 & 0,7872 & 0,6444 & 0,5435 & 0,4688 & 0,4113 & 0,3657 & 0,3285 \\
\hline 1,2 & 0,5670 & 1,0357 & 0,8737 & 0,7132 & 0,5935 & 0,5052 & 0,4383 & 0,3860 & 0,3441 & 0,3098 \\
\hline 1,25 & 0,2174 & 0,7903 & 0,7523 & 0,6409 & 0,5442 & 0,4684 & 0,4091 & 0,3620 & 0,3238 & 0,2922 \\
\hline 1,3 & 0,071139 & 0,5827 & 0,6387 & 0,5718 & 0,4969 & 0,4332 & 0,3814 & 0,3392 & 0,3046 & 0,2756 \\
\hline 1,4 & 0,0050 & 0,2895 & 0,4437 & 0,4466 & 0,4100 & 0,3684 & 0,3304 & 0,2975 & 0,2695 & 0,2454 \\
\hline 1,5 & 0,0002 & 0,1298 & 0,2957 & 0,3415 & 0,3343 & 0,3112 & 0,2852 & 0,2606 & 0,2384 & 0,2187 \\
\hline 1,6 & 0,0000 & 0,0535 & 0,1904 & 0,2567 & 0,2700 & 0,2615 & 0,2456 & 0,2280 & 0,2109 & 0,1951 \\
\hline 1,7 & 0,0000 & 0,0205 & 0,1192 & 0,1902 & 0,2164 & 0,2189 & 0,2110 & 0,1994 & 0,1867 & 0,1743 \\
\hline 1,8 & 0,0000 & 0,0074 & 0,0729 & 0,1393 & 0,1724 & 0,1826 & 0,1811 & 0,1743 & & 0,1558 \\
\hline 1,9 & 0000 & 0,0025 & 0,0437 & 0,1010 & 0,1366 & 0,1519 & 0,1552 & 0,1523 & 0,1465 & 0,1394 \\
\hline 2 & 0,0000 & 0,0008 & 0,0258 & 0,0727 & 0,1078 & 0,1261 & 0,1329 & 0,1331 & 0,1299 & 0,1249 \\
\hline 2,5 & 0,0000 & 0,0000 & 0,0016 & 0,0129 & 0,0317 & 0,0488 & 0,0609 & 0,0682 & 0,0719 & 0,0732 \\
\hline 3 & 0,0000 & 0,0000 & 0,0001 & 0,0021 & 0,0090 & 0,0187 & 0,0280 & 0,0354 & 0,0406 & 0,0439 \\
\hline \multirow{2}{*}{$\boldsymbol{K}_{P}, \mathbf{\text { в.o. }}$} & \multicolumn{10}{|c|}{ ефіціснт варіації, $C_{V}$} \\
\hline & 1,1 & 1,2 & 1,3 & 1,4 & 1,5 & 1,6 & 1,7 & 1,8 & 1,9 & 2,0 \\
\hline 0,1 & 0,9581 & 1,1032 & 1,2115 & 1,2865 & 1,3334 & 1,3576 & 1,3641 & 1,3570 & 1,3396 & 1,3147 \\
\hline 0,2 & 0,9187 & 0,9485 & 0,9570 & 0,9506 & 0,9339 & 0,9103 & 0,8823 & 0,8517 & 0,8199 & 0,7875 \\
\hline 0,3 & 0,8296 & 0,81 & 0,7880 & 0,7582 & 0,7261 & 0,6932 & 0,6605 & 0,6286 & 0,5979 & 0,5685 \\
\hline 0,4 & 0,7371 & 0,701 & 0,6638 & 0,6271 & 0,5918 & 0,5583 & 0,5268 & 0,4973 & 0,4698 & 0,4441 \\
\hline 0,5 & 0,6516 & 0,60 & 5677 & 0,5303 & & 0,4645 & 0,4357 & 0,4092 & 0,3850 & 0,3627 \\
\hline 0,6 & 5755 & 0,530 & 0,4910 & 0,4554 & 0,4235 & 0,3949 & 0,3690 & 0,3455 & 0,3242 & 0,3048 \\
\hline $\mathbf{0 , 7}$ & 0,5086 & 0,46 & 0,4284 & 0,3956 & & 0,3409 & 0,3179 & 0,2972 & 0,2784 & 0,2615 \\
\hline $\mathbf{0 , 7 5}$ & 0,4783 & 0,43 & 0,4012 & 0,3700 & 0,3426 & 0,3182 & 0,2965 & 0,2770 & 0,2595 & 0,2436 \\
\hline $\mathbf{0 , 8}$ & 0,4500 & 0,410 & 0,3764 & 0,3468 & 0,3208 & 0,2978 & 0,2774 & 0,2591 & 0,2426 & 0,2277 \\
\hline $\mathbf{0 , 8 5}$ & 236 & 0,38 & 0,3536 & 0,3256 & & 0,2794 & 0,2601 & 0,2429 & 0,2274 & 0,2134 \\
\hline 0,9 & 0,3990 & 0,36 & 0,3326 & 0,3061 & 0,2830 & 0,2626 & 0,2445 & 0,2283 & 0,2138 & 0,2006 \\
\hline $\mathbf{0 , 9 5}$ & & & & & & 0,2474 & 0,2303 & & & 0,1890 \\
\hline 1 & 3543 & 0,3 & 0,29 & 0,2719 & 514 & 0,2334 & 0,2173 & 0,2030 & 0,1901 & 0,1784 \\
\hline 1,05 & 0,3342 & 0,3043 & 0,2788 & 0,2568 & 0,2375 & 0,2205 & 0,2054 & 0,1919 & 0,1798 & 0,1688 \\
\hline 1,1 & 0,3153 & 0,2874 & 0,2635 & 0,2428 & & 0,2087 & 0,1945 & 0,1817 & 0,1703 & 0,1599 \\
\hline 1,15 & 0,2977 & 0,271 & 0,2492 & 0,2298 & 0,2128 & 0,1977 & 0,1844 & 0,1724 & 0,1616 & 0,1518 \\
\hline 1,2 & & & & & & & 0,1750 & & & 0,1443 \\
\hline 1,25 & 2656 & 0,2430 & 0,2235 & 0,2065 & 0,1915 & 0,1782 & 0,1664 & 0,1557 & 0,1461 & 0,1374 \\
\hline 1,3 & & & & 0,1960 & 0,1819 & 0,1695 & 0,1583 & 0,1482 & 0,1392 & 0,1309 \\
\hline 1,4 & 0,2247 & & & 0,1770 & 0,1647 & 0,1537 & 0,1438 & 0,1348 & 0,1267 & 0,1193 \\
\hline 1,5 & 0,2014 & 0,1861 & 0,1725 & 0,1604 & 0,1496 & 0,1399 & 0,1311 & 0,1231 & 0,1159 & 0,1093 \\
\hline 1,6 & 0,1808 & & & & 0,1363 & 0,1277 & 0,1199 & 0,1128 & 0,1063 & 0,1004 \\
\hline 1,7 & 0,1626 & 0,1517 & 0,1418 & 0,1328 & 0,1245 & 0,1170 & 0,1100 & 0,1037 & 0,0979 & 0,0925 \\
\hline 1,8 & 0,1464 & 0,1374 & & & 0,1140 & 0,1074 & 0,1012 & 0,0956 & 0,0904 & 0,0856 \\
\hline 1,9 & 0,1320 & & 0,1176 & 0,1109 & 0,1046 & 0,0988 & 0,0934 & $\begin{array}{l}0,0883 \\
\end{array}$ & 0,0837 & 0,0793 \\
\hline 2 & 0,1192 & 0,1133 & 0,1074 & 0,1017 & 0,0962 & 0,0911 & 0,0863 & 0,0818 & 0,0776 & 0,0737 \\
\hline 2,5 & & & & & & 0,0624 & 0,0599 & 0,0574 & 0,0550 & 0,0526 \\
\hline 3 & 0,0458 & 0,0466 & 0,0467 & 0,0462 & 0,0454 & 0,0443 & 0,0431 & 0,0418 & 0,0404 & 0,0390 \\
\hline
\end{tabular}


Висновки. Розроблено метод розрахунку функції диференційної щільності трипараметричного імовірнісного розподілу витрат води стоку річки на основі застосування інтерполяційної процедури з використанням сплайнів в околі полюсів гамма-функції, який дозволяє виконувати розрахунки за довільних значень коефіцієнтів варіації та асиметрії для врахування природоохоронних обмежень на використання води для виробництва електроенергії.

3 метою забезпечення можливості використання результатів проведеного дослідження інженерними та проектними службами при виконанні гідрологічних та гідротехнічних розрахунків річок 3 будь-якими гідрологічними параметрами стоку, сформовано таблиці значень функції диференційної щільності імовірнісного трипараметричного гамма-розподілу витрат води, заданих модульними коефіцієнтами $K_{P}$, за зміни коефіцієнта варіації $C_{V}$ в діапазоні $0,1 \div 2 \quad 3$ кроком 0,1 і $C_{S} / C_{V}=1 ; 1,5 ; 2 ; 2,5 ; 3 ; 3,5 ; 4$. За необхідності отримання даних при гідрологічних параметрів стоку, що не представлені в таблицях, можливе виконання інтерполяції табличних значень.

1. Васько П.Ф., Мороз А.В. Законодательные стимулы и природоохранные ограничения использования гидроэнергетических ресурсов малых рек Украины. Альтернативная энергетика и экология (ISJAEE). 2014. № 15(155). С. 82-92. ISSN 1608-8298.

2. Васько П.Ф. Сучасний стан, потенційні можливості та передумови подальшого розвитку малої гідроенергетики в Україні. Відновлювана енергетика. 2006. №1. С. 60-65.

3. Васько П.Ф., Мороз А.В. Потенціал використання гідроенергетичних ресурсів основних малих річок України. Відновлювана енергетика. 2016. № 3. С. 50-56.

4. Васько П.Ф., Ібрагімова М.Р. Основні положення створення «зелених» малих ГЕС. Тези IV міжнар. наук. практ. конф. «Оптимальне керування електроустановками OKЕУ'2017». Вінниця. 2017. [Електронний ресурс]. URL: https://conferences.vntu.edu.ua/ index.php/okeu/okeu/ paper/viewFile/3520/2979 (дата звернення: 06.05.2019).

5. Васько П.Ф., Ибрагимова М.Р. Энергетическая эффективность малой гидроэлектростанции при экологических ограничениях на использование стока воды реки для производства электроэнергии. Альтернативная энергетика и экология (ISJAEE). 2017. № 04-06(216-218). C.103-115. ISSN $1608-8298$

6. Ібрагімова М.P. Визначення проектних параметрів малої ГЕС за регулювання потужності по водотоку. Відновлювана енергетика. 2016. № 1. С. 55-60. ISSN 1819-8058.

7. Малинин Н.К. Теоретические основы гидроэнергетики. Москва. Энергоатомиздат. 1985. 312 с.

8. Васько П.Ф., Бриль А.А., Мороз А.В., Озорин Д.Ф. Расчет теоретического значения гидроэнергетического потенциала малых рек с учетом обеспеченности стока воды. Альтернативная энергетика и экология (ISJAEE). 2012. № 07(111). C .124-132. ISSN 1608-8298.

9. Блохинов Е.Г. Распределение вероятностей величин речного стока. Москва. Наука. 1974. 169 с.
10. Дружинин В.С., Сикан А.В. Методы статистической обработки гидрометеорологической информации. Учебное пособие. Направление «Гидрометеорология». Специальность «Гидрология». Санкт-Петербург. изд. РГГМУ 2001. $170 \mathrm{c}$.

11. ДБН В.2.4-8:2014 Визначення розрахункових гідрологічних характеристик. Київ: Мінрегіон України. 2015. $107 \mathrm{c}$.

12. Речной сток и его характеристики. Ремонт Строительство Интерьер. 2015. [Електронний ресурс].

URL: $\quad$ http://industrial-wood.ru/transport-lesa/6199rechnoy-stok-i-ego-harakteristiki.html (дата звернення: 06.05.2019)

13. Guiding Principles. Sustainable Hydropower Development in the Danube Basin. International Commission for the Protection of the Danube River. 2013. [Електронний ресурс]. URL: http://www.icpdr.org/main/activities-projects/hydropower (дата звернення: 24.04.2019).

14. Завьялов Ю.С., Квасов Б.И., Мирошниченко В.Л. Методы сплайн-функций. Москва. Главная редакция физико-математической литературы. 1980. 352 с.

15. Шикин Е.В., Плис Л.И. Кривые и поверхности на экране компьютера. Руководство по сплайнам для пользователей. Мщсква: ДИАЛОГ-МИФИ. 1996. 240 с.

16. Завьялов Ю.С., Леус В.А., Скороспелов Б.А. Сплайны в инженергой геометрии. Москва. Машиностроение. 1985. $224 \mathrm{c}$.

17. Яиик А.В., Бишовець Л.Б., Богатов С.О. та ін. Малі річки України: Довідник За ред. А.В. Яцика. Київ. Урожай. 1991. 296 с.

18. Справочник по водным ресурсам Под ред. Б.И. Стрельца. Киев. Урожай. 1987. 304 с.

\section{REFERENCES}

1. Vasko P.F., Moroz A.V. Zakonodatelnye stimuly i prirodookhrannye ogranicheniya ispolzovaniya gidroenergeticheskikh resursov malykh rek Ukrainy. [Legislative Incentives and Environmental Restrictions on the Use of Hydropower Resources of Small Rivers of Ukraine]. International Scientific Journal for Alternative Energy and Ecology (ISJAEE). 2014. No. 15. Pp.82-92. [in Russian].

2. Vasko P.F. Suchasnyi stan, potentsiini mozhlyvosti ta peredumovy podalshoho rozvytku maloi hidroenerhetyky $v$ Ukraini. [Current state, potential opportunities and prerequisites for the further development to smallhydropower in Ukraine]. Vidnovluvana energetika. 2006. No. 1. Pp. 60-66. [in Ukrainian].

3. Vasko P.F., Moroz A.V. Potencial vykorystannja ghidroenerghetychnykh resursiv osnovnykh malykh richok Ukrajiny. [The potential use of hydropower resources of main small rivers of Ukraine]. Vidnovluvana energetika. 2016. No. 3. Pp. 50-56. [in Ukrainian].

4. Vasko P.F., Ibragimova M.R. Osnovni polozhennja stvorennja «zelenykh» malykh GhES. [Basic regulations for construction of "green" small hydropower plants]. Abstracts of IV Scientific-practical Conf. "Optimal Control of Electrical Installations - OKEU'2017”. Vinnytsia. 2017. [Electronic resource]. URL: https://conferences.vntu.edu.ua/ index.php/okeu/okeu/ paper/viewFile/3520/2979 (Applying date: 06.05.2019). [in Ukrainian].

5. Vasko P.F., Ibragimova M.R. Jenergeticheskaja jeffektivnost maloj gidrojelektrostancii pri jekologicheskih ogranichenijah na ispolzovanie stoka vody reki dlja proizvodstva jelektrojenergii. [Energy efficiency of small hydropower plant through environmental restrictions on water use for power generation]. International Scientific Journal for Alternative Energy and Ecology (ISJAEE). 2017. No. 04-06(216-218). Pp. 103-115. 
ISSN 1608 - 8298. [in Russian].

6. Ibragimova M.R. Vyznachennja proektnykh parametriv maloji GhES za reghuljuvannja potuzhnosti po vodotoku. [Determination of design parameters of a small hydroelectric power plant for capacity regulation by water flow] Vidnovluvana energetika. 2016. No. 1. Pp. 55-60. [in Ukrainian]. 7. Malynyn N.K. Teoretycheskye osnovы ghydroэnerghetyky. [Theoretical basics of hydropower]. Moscow. Energhoatomyzdat. 1985. 312 p. [in Russian].

8. Vasko P.F., Bril A.O., Moroz A.V., Ozorin D.F. Raschet teoreticheskogo znacheniya gidroenergeticheskogo potentsiala malykh rek s uchetom obespechennosti stoka vody. [Calculation of the theoretical value of the hydropower potential of small rivers, taking into account the availability of water flow]. International Scientific Journal for Alternative Energy and Ecology (ISJAEE). 2012. No. 7. Pp.126-132. [in Russian].

9. Blokhinov E.G. Raspredelenye verojatnostej velychyn rechnogho stoka. [Probability distribution of river runoff values] Moscow. Science. 1974. 169 p. [in Russian].

10. Druzhynyn V.S., Sykan A.V. Metody statystycheskoj obrabotky ghydrometeorologhycheskoj ynformacyy. [Methods of statistical processing of hydrometeorological information]. St. Petersburg. RGGMU ed. 2001. 170 p. [in Russian].

11. DBN B.2.4-8:2014 Vyznachennja rozrakhunkovykh ghidrologhichnykh kharakterystyk. [DBN B.2.4-8: 2014 Determination of calculated hydrological characteristics]. Kyiv. Ministry of Regional Development of Ukraine. 2015. 107 p. [in Ukrainian].

12. Rechnoj stok y egho kharakterystyky. [The river flow and its characteristics]. Repair Construction Interior. 2015. [Electronic resource]. URL: http://industrial-wood.ru/transportlesa/6199-rechnoy-stok-i-ego-harakteristiki.html (Applying date: 06.05.2019). [in Russian].

13. Guiding Principles. Sustainable Hydropower Development in the Danube Basin. International Commission for the Protection of the Danube River, 2013. [Electronic resource] URL: http://www.icpdr.org/main/activities-projects/hydropower (Applying date: 24.04.2018). [in English].

14. Zavyalov Yu.S., Kvasov B.I., Miroshnichenko V.L. Metody splajn-funkcyj. [Methods of spline functions]. Moscow. The main edition of the physical and mathematical literature. 1980. 352 p. [in Russian].

15. Shikin E.V., Plis L.I. Kryvye y poverkhnosty na ekrane kompijutera. Rukovodstvo po splajnam dlja poljzovatelej. [Curves and surfaces on a computer screen. Spline guide for users]. Moscow. DIALOGUE-MIFI. 1996. 240 p. [in Russian].

16. Zavyalov Yu.S., Leus V.A., Skorospelov B.A. Splajny v ynzhenerghoj gheometryy. [Splines in engineering geometry]. Moscow. Engineering. 1985. 222 p. [in Russian].

17. Yatsik A.V., Byshovets L.B., Rich E.O. and others. Mal richky Ukrajiny: Dovidnyk. [Small Rivers of Ukraine: Handbook]. Kyiv. Urozhaj. 1991. 296 p. [in Ukrainian].
18. Streljc B.Y. Spravochnyk po vodnym resursam. [Handbook of Water Resources]. Kyiv. Urozhaj. 1987. 304 p. [in Russian].

\section{МЕТОД РАСЧЕТА ДИФФЕРЕНЦИАЛЬНОИ ПЛОТНОСТИ ВЕРОЯТНОСНОГО ТРИПАРАМЕТРИЧЕСКОГО ГАММА- РАСПРЕДЕЛЕНИЯ РАСХОДОВ СТОКА РЕКИ В ЗАДАЧАХ ГИДРОЭНЕРГЕТИКИ}

\section{М.Р. Ибрагимова}

Институт возобновляемой энергетики НАН Украины, 02094, г. Киев, ул. Гната Хоткевича, 20A

тел./факс: +38-044-206-28-09, e-mail: hydro@ive.org.ua

Ожидаемый в ближайшем будущем дефицит углеводородов, растущее давление на экологию и ресурсообеспечения существования человечества - основные тригzеры трансформачии энергетической отрасли. Развитие малой гидроэнергетики также должно соответствовать рациональному использованию водного ресурса, сохранению и возможному восстановлению речной системы, минимизации антропогенного воздействия. Данная статья направлена на решение актуального вопроса создания мальх гидроэлектростанций, технологические режимы работы которых соответствуют принципам рачионального гидроэнергетического водопользования с учетом природоохранных ограничений на использование воды для производства электроэнергии. Автором приведень преимущества использования функции дифференциальной плотности вероятностного распределения расходов стока реки над традиционно применяемой интегральной функиией распределения при анализе гидроэнергетических показателей эксплуатаиии мальхх ГЭС. Проведенный анализ предыдущих исследований дифференциальной плотности показал отсутствие обобщенных результатов по определению данной функиии в виде, необходимом для дальнейших практических применений. Впервые разработан метод расчета функциии дифференци альной плотности вероятностного трехпараметрического гамма-распределения расходов стока реки при произвольныхх значениях коэффициентов вариации и асимметрии на основе применения интерполяиии кубическими сплайнами в окрестности полюсов гамма-функиии. Материаль статьи содержат результаты проведенного исследования в виде таблиц значений функиии дифференцииальной плотности вероятностного гамма-распределения расходов воды. Указанные таблииы рекомендуются к применению инженерными и проектными службами при выполнении гидрологических и гидротехнических расчетов в задачах гидроэнергетики. Библ. 18, табл. 3, рис. 3.

Ключевые слова: расходы воды, вероятность, интерполяичия, дифференциальная плотность, обеспеченность, распределение. 